\title{
Microanalysis of Trace Evidence in an Airbag Injury Case
}

\author{
S.F. Stoeffler
}

Light Microscopy Section-McCrone Associates, 850 Pasquinelli Drive, Westmont, IL 60559-5539

In 1999, a near head-on collision occurred in Mississippi between a Plymouth Neon and a truck. Both airbags of the Neon deployed and driver suffered severe chemical burns in the face and neck area. The burns were diagnosed as having been caused by a strong alkali material, and a lawsuit was initiated, claiming that caustic effluent from the airbag inflator (which used sodium azide) had vented into the passenger compartment and caused the driver's injuries. McCrone Associates was asked to examine the airbags and other evidence in the case to evaluate this claim.

Microscopical examination of the airbags showed extensive patterns of whitish, crusty deposits. When viewed with ultraviolet light, clear patterns of high velocity liquid spatter were seen on both bags, corresponding to the crusty areas (Fig 1). The crusty areas were determined by infrared microspectroscopy to be nylon, similar to that making up the airbag fibers, which had apparently been melted or dissolved.

Further examination of the material in the whitish spatter areas by scanning electron microscopy with backscattered electron imaging and energy dispersive x-ray spectroscopy/wavelength dispersive spectroscopy revealed large numbers of tiny particles rich in lead and sulfur, as well as clear patterns of chemical attack on the fibers (Figs 2-4). No sodium-rich particles consistent with the expected residue from the airbag inflator were detected. This suggested that the damage to the airbags and the driver's injuries had been caused by acid from a vehicle battery, which was the only source of lead and sulfur in the accident. Further examination of the Neon driver's jeans, which had extensive patterns of holes, and testing of exemplar jeans, confirmed that this damage was also consistent with a strong acid, but not a strong alkali. Testing on exemplar airbags also demonstrated that the damage seen in the Neon airbags could not have been caused by a strong alkali like sodium hydroxide.

Various theories advanced by plaintiff's experts to explain these anomalies, including the suggestion that the particles were molybdenum disulfide, could not be reconciled with the results of testing on the airbags and exemplar samples (Fig 5). It was concluded that the driver's injuries were due to battery acid sprayed into the passenger compartment of the Neon from the shattered battery of the striking vehicle.

[1] The author gratefully acknowledges the assistance of Joe Barabe and Wayne Niemeyer of McCrone Associates with photography and WDS analysis. 


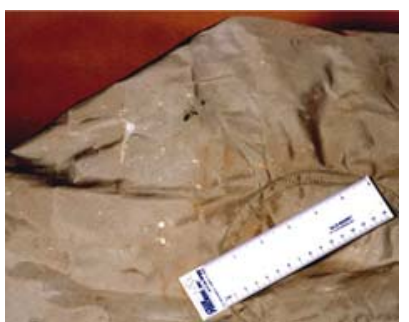

a

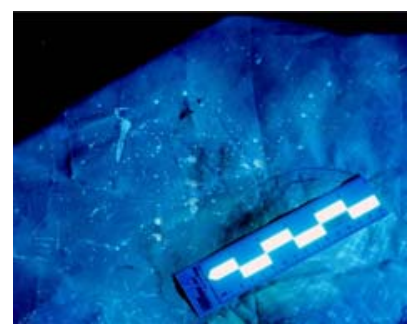

b

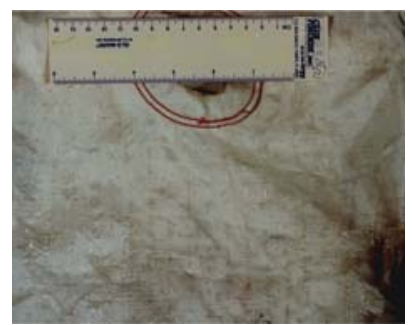

c

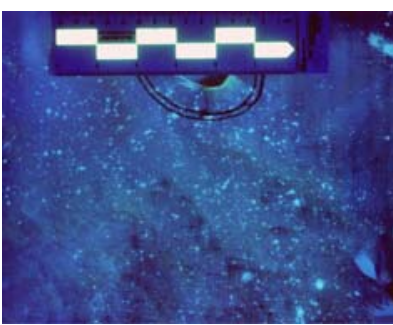

d

Figure 1. Airbags from Plymouth Neon a) driver's airbag, b) driver's airbag-UV light, c) passenger airbag, d) passenger airbag-UV light

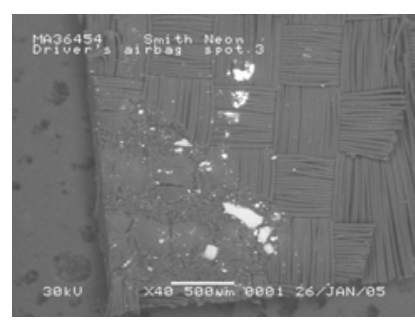

Figure 2. SEM Images of deposits on driver's airbag-BEI

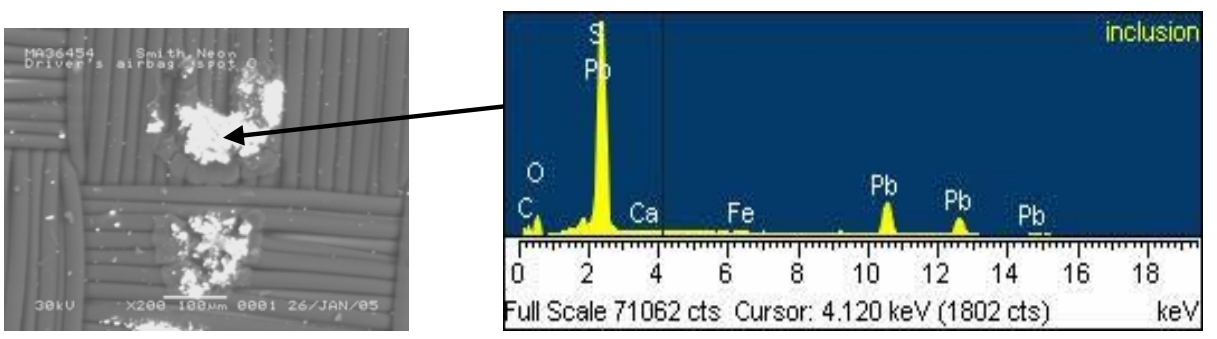

Figure 3. Energy dispersive x-ray spectrum of particle in deposit of Figure 2

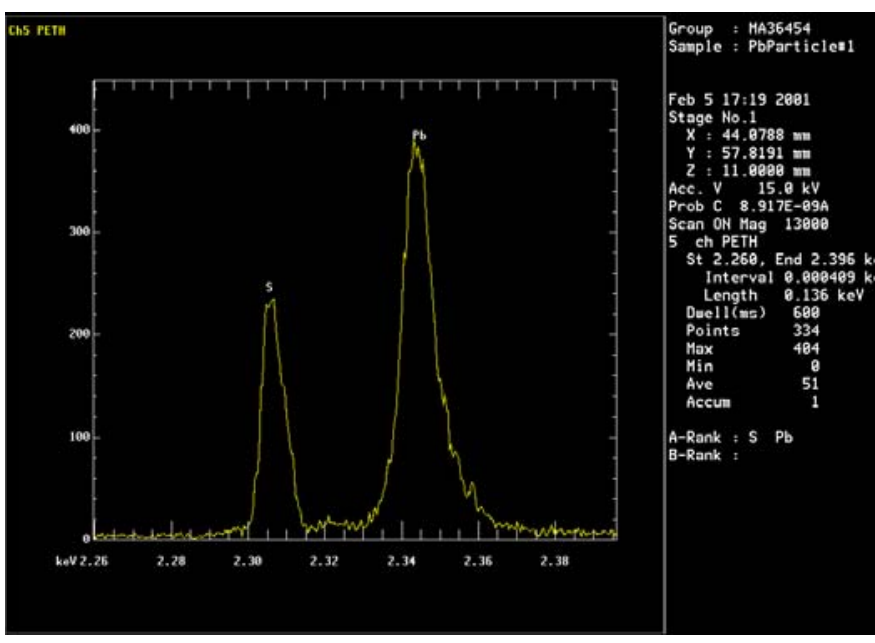

Figure 4. Wavelength dispersive $\mathrm{x}$-ray spectrum of particle in deposit of Figure 2

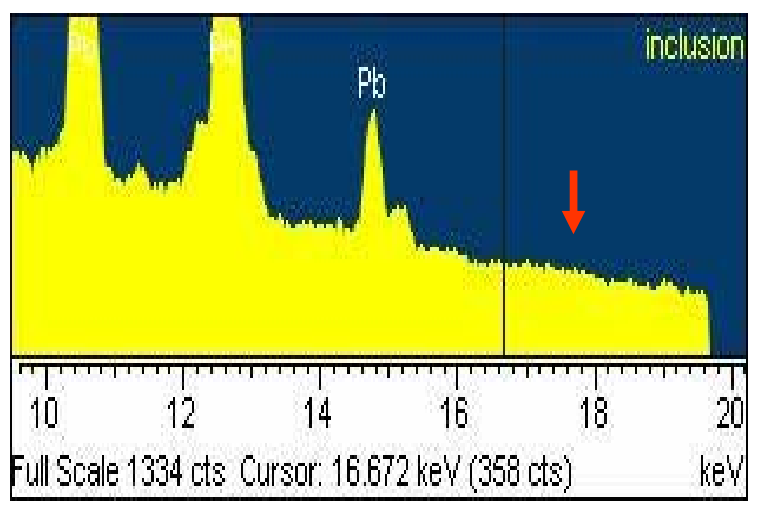

Figure 5. Expanded plot of Figure 3, showing absence of $\mathrm{Mo} \mathrm{K}_{\alpha}$ line 